\title{
SOLiD sequencing of four Vibrio vulnificus genomes enables comparative genomic analysis and identification of candidate clade-specific virulence genes
}

\author{
Paul A Gulig ${ }^{1 *}$, Valérie de Crécy-Lagard ${ }^{2}$, Anita C Wright ${ }^{3}$, Brandon Walts ${ }^{1}$, Marina Telonis-Scott ${ }^{1,4}$, \\ Lauren M Mclntyre ${ }^{1}$
}

\begin{abstract}
Background: Vibrio vulnificus is the leading cause of reported death from consumption of seafood in the United States. Despite several decades of research on molecular pathogenesis, much remains to be learned about the mechanisms of virulence of this opportunistic bacterial pathogen. The two complete and annotated genomic DNA sequences of $V$. vulnificus belong to strains of clade 2, which is the predominant clade among clinical strains. Clade 2 strains generally possess higher virulence potential in animal models of disease compared with clade 1, which predominates among environmental strains. SOLiD sequencing of four $V$. vulnificus strains representing different clades (1 and 2) and biotypes (1 and 2) was used for comparative genomic analysis.
\end{abstract}

Results: Greater than 4,100,000 bases were sequenced of each strain, yielding approximately 100-fold coverage for each of the four genomes. Although the read lengths of SOLiD genomic sequencing were only $35 \mathrm{nt}$, we were able to make significant conclusions about the unique and shared sequences among the genomes, including identification of single nucleotide polymorphisms. Comparative analysis of the newly sequenced genomes to the existing reference genomes enabled the identification of 3,459 core $V$. vulnificus genes shared among all six strains and 80 clade 2-specific genes. We identified 523,161 SNPs among the six genomes.

Conclusions: We were able to glean much information about the genomic content of each strain using next generation sequencing. Flp pili, GGDEF proteins, and genomic island XII were identified as possible virulence factors because of their presence in virulent sequenced strains. Genomic comparisons also point toward the involvement of sialic acid catabolism in pathogenesis.

\section{Background}

Vibrio vulnificus is an opportunistic pathogen that causes sepsis in humans after ingestion of contaminated raw oysters or wound infection and necrotizing fasciitis from contamination of wounds (for a review see $[1,2]$ ). The mortality rates for sepsis and wound infection are $\sim 50 \%$ and $\sim 15 \%$, respectively. During infection of humans the bacteria replicate rapidly, extensively invade tissues, and cause severe tissue destruction. Mouse models of infection coupled with molecular genetic analysis

\footnotetext{
* Correspondence: gulig@ufl.edu

'Department of Molecular Genetics and Microbiology, University of Florida, Gainesville, Florida, USA

Full list of author information is available at the end of the article
}

have identified several virulence factors partially explaining the high mortality and extreme tissue destruction, most importantly, polysaccharide capsule [3,4], RtxA1 toxin [5-7], acquisition of iron [8,9], pili [10,11], and flagella $[12,13]$. However, these factors do not completely explain the remarkable virulence of $V$. vulnificus.

$V$. vulnificus can be classified in several different manners. One of the first classification schemes was based on biochemical reactions of strains initially yielding two biotypes: biotype 1 most often associated with contamination of oysters and causing human disease and biotype 2 associated with infection of eels [14]. Recently, a third biotype that caused wound infection from handling fish in Israel was identified [15]. Genetic analysis using 
analysis of ribosomal RNA loci $[16,17]$, multilocus sequence typing (MLST) [18-20], and virulence-correlated gene $(v c g)$ PCR [21] revealed that $V$. vulnificus strains could be divided into two groups. While the descriptors for these two groups vary (clades, populations, clusters, and lineages), the terms clade 1 and clade 2 are used here to follow the MLST clusters of Bisharat et al. [19]. Biotype 1 strains are present in both clades, whereas biotype 2 strains are present only in clade 1. Based on MLST analysis, biotype 3 strains appear to be a hybrid between clades 1 and 2 [18]. Clade 1 strains are most often isolated from environmental samples, while clade 2 strains are most often associated with human disease. Because of these epidemiological patterns, many investigators hypothesized that clade 2 strains possess inherently greater virulence. In an analysis of 69 biotype $1 \mathrm{~V}$. vulnificus strains, we recently determined that both clade 1 and clade 2 strains have the ability to cause severe skin infection in subcutaneously inoculated iron dextran-treated mice (Thiaville, P.C. et al., Infect. Immun, submitted; Jones, M. et al., in preparation). The major distinction between the clades was that clade 2 strains had a greater propensity to cause systemic infection and death in the mouse model, although there were some attenuated clade 2 strains and highly virulent clade 1 strains.

Analysis of the genomic DNA sequences of clade 1 and clade 2 strains would contribute to the identification of genetic differences among strains. As microbes engage in lateral gene transfer and are often highly divergent in genomic content, this study could help identify genes responsible for the differences in virulence between these clades. Both of the complete and annotated $V$. vulnificus genomes are of clade 2 strains, CMCP6 (GenBank accession numbers AE016795 and AE016796) and YJ016 (GenBank accession numbers BA000037, BA000037, AP005352). The lack of genomic sequence data from clade 1 strains is a serious impediment to understanding the differences in virulence between the two clades and in dissecting the virulence of $V$. vulnificus in general. We therefore undertook the present study to rapidly and economically obtain genomic sequence of numerous $V$. vulnificus strains representing both clades and the two major biotypes.

We hypothesized that clade 2 strains are more virulent, at least in part, because they contain unique virulence genes that are missing in most clade 1 strains. Therefore, identifying DNA sequences common to clade 2 strains and missing from clade 1 strains would create a set of putative virulence genes that could be subsequently experimentally examined. Because of the propensity of clade 1 strains to be associated with oysters, these strains may possess unique genes enabling colonization of shellfish. Therefore, unique clade 1 genes offer insight into the Vibrio-oyster relationship. However, not all genes uniquely associated with one clade will be involved with interactions with animal hosts, and virulence genes will not necessarily be present only in virulent genotypes. An example of the former is that the ability of $V$. vulnificus to ferment mannitol is associated with the cluster of strains that we are calling clade 2 most often derived from clinical cases [22], and an example of the latter is the nearly universal presence of the RtxA1 toxin in both virulent and attenuated $V$. vulnificus strains (Joseph, J.L., et al., in preparation). Finally, by comparing the genomes of a variety of strains representing the different clades and biotypes, the set of genes in the $V$. vulnificus genome shared by all $V$. vulnificus strains can be identified. Over and above identifying relationships between the presence and/or absence of genes among strains, identifying single nucleotide polymorphisms (SNPs) could also reveal the genetic basis for differential virulence and shellfish-colonizing phenotypes, as well as other phenotypes.

Given these goals, we used the SOLiD sequencing system on four $V$. vulnificus strains, each of which represented a unique genotype/virulence phenotype combination (Table 1). V. vulnificus M06-24/O [4] is a typical clade 2 strain exhibiting a high level of virulence in the subcutaneously inoculated iron dextran-treated mouse model [23-25]. Strain 99-520 DP-B8 [25] is a typical clade 1 strain that can infect skin tissues but is defective at causing systemic infection and death in the mouse model. Strain 99-738 DP-B5 [25] is an unusual clade 1 strain that is highly virulent in the mouse

Table 1 Genotypes and virulence phenotypes of the $V$. vulnificus strains whose genomes were sequenced in this study*

\begin{tabular}{|c|c|c|c|c|c|c|c|c|}
\hline Strain & Source & Biotype & MLST* $^{*}$ & $v c g^{*}$ & $r r n$ & rep-PCR* & Skin Infection & Liver Infection/Death \\
\hline M06-24/O & Clinical & 1 & 2 & C & B & 8 & + & + \\
\hline 99-520 DP-B8 & Oyster & 1 & 1 & $E$ & $A B$ & 7 & + & - \\
\hline 99-738 DP-B5 & Oyster & 1 & 1 & $E$ & A & 7 & + & + \\
\hline ATCC 33149 & Eel & 2 & 1 & $E$ & $A$ & 5 & - & - \\
\hline
\end{tabular}

*Virulence data for biotype 1 strains are from Thiaville, P.C., et al. (Infect. Immun., submitted) and for ATCC 33149 are from this study. MLST, vcg, and rep-PCR data are from Mahmud, et al. [83]. rrn data for biotype 1 strains are from Thiaville, P.C., et al. (Infect. Immun., submitted) and for ATCC 33149 are from Vickery et al. [84]. 
model, causing systemic infection and death. ATCC 33149 [26] is typical biotype 2 strain isolated from an eel. Using SOLiD sequencing enabled us to obtain approximately 100X coverage with 35 -nt reads among four genomes. This selection of strains analyzed with SOLiD sequencing enabled comparative genomics to be performed and identified clade 2-specific genomic sequences and the genes of $V$. vulnificus shared among all of the strains sequenced to date.

\section{Results}

\section{Numbers of SOLiD sequencing reads}

We performed SOLiD sequencing on the genomes of four $V$. vulnificus strains to increase the understanding of the genetic differences between the two major clades and the biotypes of this organism and to possibly identify sequences associated with differences in virulence potential in our subcutaneously inoculated iron dextrantreated mouse model [23-25]. $V$. vulnificus 99-520 DPB8 and 99-738 DP-B5 are clade 1 strains, typically isolated from environmental sources. Strain 99-520 DP-B8 exhibits the typical attenuated virulence of clade 1 strains, i.e., it can cause skin infection but is defective at causing systemic infection and death. In contrast, strain 99-738 DP-B5 exhibits a high level virulence more characteristic of clade 2 strains, i.e., it causes skin infection, systemic infection, and death (Thiaville, P.C., et al., Infect. Immun., submitted). V. vulnificus M06-24/O is a typical clade 2 strain with full virulence that has been widely used in examining molecular pathogenesis by many laboratories [4]. V. vulnificus ATCC 33149 is a biotype 2 strain isolated from an eel [26]. Genomic DNA from each of these strains was loaded onto one-fourth of a $25 \mathrm{~mm} \times 75 \mathrm{~mm} \mathrm{SOLiD}{ }^{\mathrm{mm}}$ slide for sequencing on an Applied Biosystems SOLiD ${ }^{\text {tw }}$ apparatus at the University of Florida Interdisciplinary Center for Biotechnology Research, as described in the Methods. The total numbers of 35-bp reads for each strain were as follows: 99520 DP-B8 - $3.16 \times 10^{7}, 99-738$ DP-B5 - $3.21 \times 10^{7}$, M06-24/O - $3.50 \times 10^{7}$, and ATCC $33149-3.38 \times 10^{7}$. These totals represented putative 210 - to 239 -fold coverage of each of the genomes, on the assumption that all of the data were usable. The reads from each of the four newly sequenced genomes have been deposited into the NCBI Short Read Archive (accession number SRA009283.2).

\section{Comparison of SOLiD sequencing reads to reference $V$. vulnificus genomes}

Reads were mapped onto the two reference $V$. vulnificus genomes, CMCP6 and YJ016 using MAQ [27]. This analysis enabled the identification of DNA sequences and ORFs that were present in the newly sequenced strains that have already been described in the reference strains. Graphical representation of the coverage of the CMCP6 and YJ016 genomes by the reads from each of the four newly sequenced $V$. vulnificus strains is shown in Figure 1.

We then mapped reads to plasmids described for biotype $2 \mathrm{~V}$. vulnificus and whose DNA sequences are known (pR99, pC4602-1, and pC4602-2) [28]. As expected, greater than $90 \%$ of all three of these reference sequences were matched to reads from biotype 2 ATCC 33149, and lesser homologies were observed for the biotype 1 strains (Additional File 1, Table S1). For clade 1 strains, between 37 and $56 \%$ of these plasmid sequences matched with 99 738 DP-B5, and only 6 to $20 \%$ of plasmid sequenced matched the SOLiD reads from strain 99-520 DP-B8. These results suggested that 99-738 DP-B5 would have a plasmid, whereas 99-520 DP-B8 would not, and we confirmed this by gel electrophoresis of extracted plasmid DNA (data not shown). The reads from strain M06-24/O, which is a clade 2 strain and least related to the other strains, only matched to $1 \%$ of plasmid pC4602-1 and failed to match to any sequences of plasmids pC4602-2 and pR99. This is in agreement with M06-24/O not having a plasmid [29].

Despite the prediction of approximately 210 -fold coverage based on the raw number of reads obtained for each genome, coverage was actually on the order of 100 -fold. In total, $45 \%$ to $64 \%$ of the raw sequencing reads mapped to one of the two reference genomes, leaving a considerable number of unmapped reads. Some of these reads were of low complexity and may represent sequencing error. Because approximately $14 \%$ of both CMCP6 and YJ016 are low complexity, these unmapped reads also may be derived from regions of low complexity in the sequenced genomes. It is a limitation of the short read technology that we cannot distinguish among these scenarios. For the remaining unmapped reads that were not of low complexity, there are two possibilities: these reads represented truly unique sequences for the newly sequenced genomes or these reads were errors in the sequencing system. In an attempt to separate these two possibilities, these unmapped reads were compared to several bacterial genomes by mapping the reads in SOLiD colorspace using MAQ [27]. This would identify orthologs of $V$. vulnificus strains in other species. The largest number of matches $(273,045)$ was found with the genomic sequence of $V$. cholerae NC16961 (GenBank accession numbers AE003852 and AE003852). (Additional File 2, Table S2). These $V$. cholerae matches yielded 20 genes in total from the four sequenced genomes. Of these $V$. cholerae genes, sixteen were identified from only a single $V$. vulnificus strain. Other novel genes may still be found, but they would be genes not previously identified in any other bacterial genomes.

There were between 15 and 22 million unmatched reads for each of the newly sequenced genomes. The 

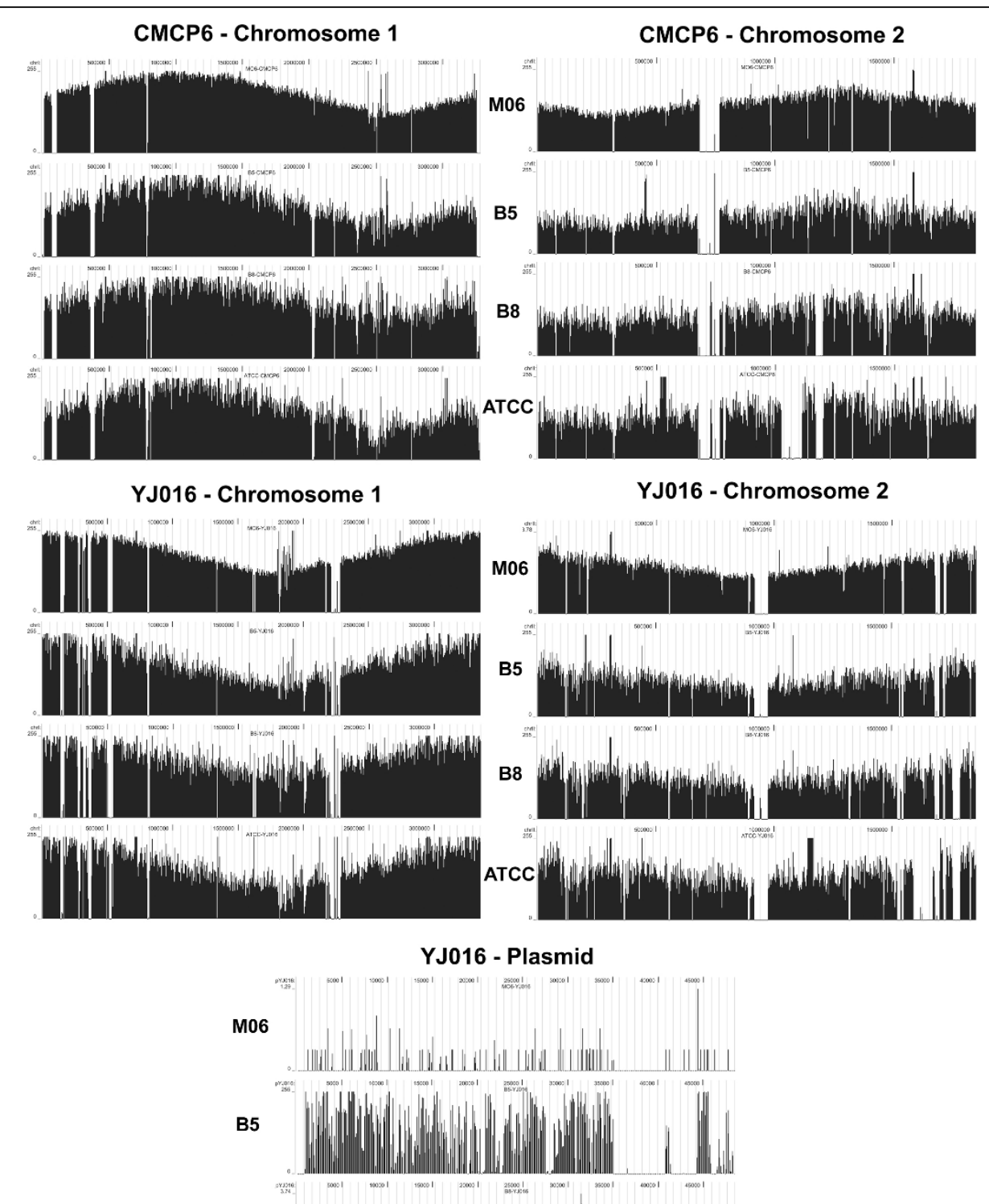

B8

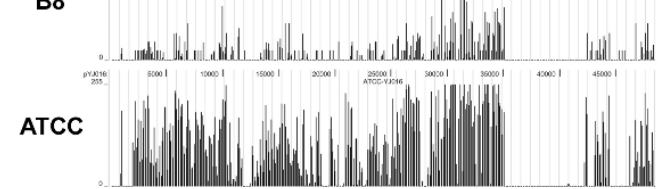

Figure 1 Graphical representation of coverage of the reference genome components by sequences of each of the four newly sequenced genomes. The depth of coverage (number of matched 35-nt reads per 100-nt window of the reference genomes) is plotted for both chromosomes of the reference CMCP6 and YJ016 genomes and the YJ016 plasmid. The source strain for the reads being matched are as follows: M06 - M06-24/O, B5 - 99-738 DP-B5, B8 - 99-520 DP-B8, ATCC - ATCC 33149. It should be noted that coverage of the reference genomes is not as continuous as it appears in the figures.

cause of such a large amount of data with no similarity to known genes cannot be explained by low complexity alone, as many of these reads are not of low complexity. While it remains possible that novel genes are included in these data, it is also possible that these reads are just noise from the technology.
Figure 1, which graphically shows the coverage of the reference genome elements by each of the newly sequenced genomic reads, reveals large regions on each of the reference genomic elements for which there were no matched reads from each of the newly sequenced genomes. Detailed comparisons of coverage generated 
lists of the genes of CMCP6 and YJ016 lacking significant depth of coverage from the newly sequenced reads (Additional File 3, Table S3A and Additional File 4, Table S3B, respectively). There were 309 ORFs unique to CMCP6 and 489 ORFS unique to YJ016 relative to the other five sequenced strains. In CMCP6 chromosome 1, two large regions that were not present in any of the four newly sequenced genomes included genes VV1_0063 to VV1_0124 and VV1_0374 to VV1_0400. These regions, which were also missing from YJ016, appear to encode phage genomes. They contain genes annotated as bacteriophage phi 1.45 protein-like protein (VV1_0066), P2-like prophage tail protein $\times$ (VV1_0086), phage integrase (VV1_0372), or they resembled other mobile genetic elements with putative transposases (VV1_0385, VV1_0386).

Another CMCP6-specific region spanned the beginning and ends of chromosome 1 (genes VV1_0001 to VV1_0011 and VV1_3192 to VV1_3205). This region also appeared to encode a phage or other mobile genetic element. A smaller CMCP6-specific region located at genes VV1_0777 to VV1_0781 appeared to encode sugar metabolism genes possibly involved in lipopolysaccharide (LPS) or capsular biosynthesis. CMCP6 chromosome 2 contained a very large region at genes VV2_0630 to VV2_0712 not present in any other strains. This region appeared to have been derived from a mobile genetic element, either a phage or transposon. There were also smaller regions unique to CMCP6 on chromosome 2.

The YJ016 genome similarly contained numerous regions that were not present in any of the other newly sequenced genomes. On chromosome 1, YJ016-specific genes were located at VV0130 to VV0165, VV0343 to VV0367, VV0514 to VV0559, VV0799 to VV0817, and VV2191 to VV2262. The largest of these YJ106 regions at VV2191 to VV2262 appeared to be phage-related. A similar pattern was evident for YJ016 chromosome 2. A very large YJ106-specific region spanning VVA0825 to VVA0888 was notable. This region consisted mainly of hypothetical proteins, but there is a possibility that this region is phage-related, as VVA0886 is annotated as a phage integrase.

The coverage of the YJ106 plasmid, which encodes 69 genes, was very different among the four newly sequenced genomes. The genomes containing the most matches were 99-738 DP-B5 and ATCC 33149, with 50 and 44 genes, respectively, matched to the YJ016 plasmid. As expected, both 99-738 DP-B5 and ATCC 33149 contain plasmids. None of the YJ016 plasmid genes matched to the reads of $99-520 \mathrm{DP}-\mathrm{B} 8$ or M06-24/O, neither of which contains plasmids.

$V$. vulnificus, like other Vibrio species, encodes a super-integron on its large chromosome [30]. Integrons are specific regions of genomic sequence that have the ability to accumulate gene cassettes via site-specific recombination [31]. They are located in genomes at attI sites and contain a site-specific integrase, intI, that mediates acquisition of gene cassettes at repetitive attC sites, which are generally conserved among closely related bacteria. The vibrio integrons are called super-integrons because of their unusually large sizes [32]. In CMCP6 the super-integron spans genes VV1_2401 to VV1_2501, and in YJ016 the super-integron spans genes VV1745 to VV1941. As shown in Additional File 3, Table S3A and Additional File 4, Table S3B, the genes encoded within these super-integrons are mostly strain-specific, not having significant homology with the four newly sequenced genomes or each other. It is interesting that the superintegrons did not appear in Figure 1 as missing from the newly sequenced genomes, most likely because of the attC sites and presence of infrequent homologous genes between the genomes.

In contrast to identifying sequences missing from the newly sequenced genomes, we also identified the genes shared among all of the six genomes, thereby identifying the core $V$. vulnificus genome. Up to this point, shared genes based on the two reference genomes numbered 3,915 genes. Adding our four newly sequenced genomes, there are 3,459 genes common to all sequenced $V$. vulnificus strains, listed in Additional File 5, Table S4. The number of shared genes can only get smaller as more genomes are sequenced. Since there are 4,473 proteincoding genes in the CMCP6 genome and 5,024 proteincoding genes in the YJ016 genome, but only 3,915 genes shared between them, there is clearly an enormous amount of strain-specific sequence among these clade 2 strains. The frequency of hypothetical proteins in the core genome was $20.3 \%$ compared with the overall frequency of $23.6 \%$ in the CMCP6 genome.

The total number of genes obtained by combining the CMCP6 and YJ016 reference genomes and excluding redundancy is 5,630. Among the 4,473 genes in the CMCP6 genome, 309 (6.9\%) were unique to this strain, and among the 5,026 genes in the YJ016 genome, 489 (9.7\%) were unique to this strain relative to all of the other genomes. By combining the matches for each strain with the reference genomes we identified the following numbers of genes for each strain: ATCC 33149 4,184; 99-738 DP-B5 - 4,359; 99-520 DP-B8 - 4,225; and M06-24/O - 4,534.

\section{Genomic inference of different $V$. vulnificus genotypes}

We asked which genes were common only to the three biotype 1/clade 2 strains, but not present in the two biotype 1 /clade 1 strains or the biotype 2 strain, because this could help identify the genes that are responsible for the increased virulence of clade 2 strains (Thiaville, P.C. et al., Infect. Immun., submitted). The 80 clade 2 - 
specific genes are listed in Table 2. Among the notable clade 2-specific genes and regions are several GGDEF proteins (genes VV1_2061, VV1_2228, VV1_2321 in the CMCP6 genome) and a Flp pilus-coding region (genes VV1_2330 to VV1_2337 in the CMCP6 genome). GGDEF proteins are involved with signal transduction in many bacteria by regulating intracellular levels of the signaling molecule cyclic-di-GMP [33], and Flp pili could be involved with adherence or genetic exchange [34]. Hypothetical proteins comprised $36.3 \%$ of the clade 2 -specific genes, compared with the overall frequency of $23.6 \%$ of hypothetical proteins in the CMCP6 genome. Because the reference strains are both clade 2, any clade 1 -specific genes will be missed in this initial mapping.

Strain 99-520 DP-B8 is a typical clade 1 strain with attenuated virulence, while strain 99-738 DP-B5 is a clade 1 strain with high virulence typical of clade 2 strains. There were 61 genes in 99-738 DP-B5 that were common to the three clade 2 strains but missing from attenuated clade 1 strain 99-520 DP-B8 and biotype 2 strain ATCC 33149. (Table 3). This set of genes could contain virulence genes acquired by 99-738 DP-B5 that endow it with clade 2 -like virulence. Hypothetical proteins comprised $19.7 \%$ of this set of genes, compared with the overall frequency of $23.6 \%$ hypothetical proteins in the CMCP6 genome. It is noteworthy that the clade $2+99-738$ DP-B5 specific set of genes includes genomic island XII identified by Cohen et al. [20] as being present in most clade 2 strains and missing from most clade 1 strains (genes VV2_1090 to VV2_1111 on the CMCP6 genome). They hypothesized that genomic island XII could be responsible for the putative differential virulence of clade 2 strains, evidenced by their association with clinical cases.

Within genomic island XII are paralogs of galactose utilization genes (VV2_1095, a paralog of galE2 encoding UDP-glucose 4-epimerase and VV2_1094, a paralog of galT2 encoding galactose-1-phosphate uridylyltransferase) that are in an operon with a predicted sulfate transporter (VV2_1096). The canonical galE (VV1_1770) and galT (VV1_1771) are located elsewhere in the galETKM operon (VV_1770 to VV1_1773). The presence of additional galET genes in a subset of $V$. vulnificus strains with high virulence suggests a role for these genes in another metabolic pathway possibly benefitting the bacteria during infection.

The link with sulfate metabolism was intriguing because five other genomic island XII genes are annotated as arylsulfatase A (VV2_1106, VV2_1108, VV2_1109, and VV2_0151) or alkyl sulfatase (VV2_0989). These enzymes hydrolyze the sulfate from sulfated gangliosides (sulfatides). VV2_1098 and VV2_1110 in the genomic island encode chondroitinases (although they are not annotated as such in the reference genome sites). Sulfatides are important components of connective tissue involved with cell adhesion [35] and serve as the receptors for various microbial pathogens ranging from HIV [36], Bordetella pertussis [37], and Helicobacter pylori [38]. An arylsulfatase of E. coli $\mathrm{K} 1$ is necessary for invasion of the blood-brain barrier [39]; hence, such activity in virulent $V$. vulnificus strains could enable invasion through tissues, which is characteristic of $V$. vulnificus infection. In clinical $V$. vulnificus isolates, the presence of region XII, encoding arylsulfatases, chondroitinases, sulfate transport, and sulfate metabolism functions, suggests that this region may have an important scavenging function removing sulfate groups from host components, thereby providing sulfur and/or carbon sources, which could facilitate survival in the human host where free sulfur is limited. However, as noted above, some of the degradative enzymes in genomic island XII could also be involved in invasion of tissues. Cohen et al. [20] had noted the presence of such genes in genomic island XII predominant in the clade of $V$. vulnificus strains most associated with clinical strains. The exclusive presence of all of these genes in clade 2 plus the highly virulent clade 1 strain 99-738 DP-B5 suggests a role in virulence. The dissection of the roles in virulence, if any, played by these genomic island XII genes identified through our comparative genomic analysis will await construction and analysis of specific mutants. However, Bryant et al. [40] described the use of sodium dodecyl sulfate-polymyxin B-sucrose plates for the identification of $V$. vulnificus from shellfish samples. The ability of bacteria to form halos around colonies on this medium is indicative of alkyl sulfatase activity. In contrast to our determination that VV2_0989 is absent in the biotype 2 strain ATCC 33149 and clade 1 strain 99-520 DP-B8 and the results of Cohen et al. [20] similarly describing the limited presence of genomic island 12 among $V$. vulnificus strains, Bryant et al. observed that all $20 \mathrm{~V}$. vulnificus strains examined possessed alkyl sulfatase activity. However, VV2_0885 and VV2_1032 are also annotated as alkyl sulfatase. Our results show that VV2_0885 is present in all six strains except 99-738 DP-B5 and VV2_1032 is present in all six strains. Hence, it would be expected that all $V$. vulnificus strains would exhibit alkyl sulfatase activity, in agreement with Bryant et al. [40].

Also of note in the clade 2 plus 99-738 DP-B5-specific genes not present in genomic island XII were linked genes possibly involved with sialic acid catabolism: N-acetylneuraminate lyase (NanA, VV2_0730), a TRAP transport system possibly involved with sialic acid transport (VV2_0731 to VV2_0733), N-acetylmannosamine-6-phosphate 2-epimerase (NanE, VV2_0734), N-acetylmannosamine kinase (NanK, VV2_0735), and N-acetylglucosamine-6-phosphate deacetylase (NagA, VV2_0736). Because the nagB gene 
Table 2 Clade 2-specific genes

\begin{tabular}{|c|c|c|c|}
\hline Tag & Product & Gene & $\operatorname{Cog}$ \\
\hline W1_0456 & putative transcriptional regulator & - & COG0583K \\
\hline W1_0457 & hypothetical protein W1_0457 & - & - \\
\hline W1_0458 & hypothetical protein W1_0458 & - & - \\
\hline W1_0459 & hypothetical protein W1_0459 & - & - \\
\hline W1_0465 & exopolyphosphatase & - & COG0248FP \\
\hline W1_0515 & hypothetical protein W1_0515 & - & COG3930S \\
\hline W1_0766 & hypothetical protein W1_0766 & - & - \\
\hline W1_0789 & hypothetical protein W1_0789 & - & - \\
\hline W1_1090 & hypothetical protein W1_1090 & - & - \\
\hline W1_1094 & chromosome segregation ATPase & - & - \\
\hline W1_1095 & Serine/threonine protein kinase & - & COG0515RTK \\
\hline W1_1518 & 3-methyladenine DNA glycosylase & - & COG0122L \\
\hline W1_1751 & hypothetical protein W1_1751 & - & - \\
\hline W1_2031 & $\begin{array}{l}\text { Type I restriction enzyme EcoEl M } \\
\text { protein }\end{array}$ & - & COG0286V \\
\hline W1_2037 & $\begin{array}{l}\text { Type I restriction enzyme EcoEl } \mathrm{R} \\
\text { protein }\end{array}$ & - & 696V \\
\hline W1_2038 & transcriptional regulator & - & - \\
\hline W1_2061 & $\begin{array}{l}\text { GGDEF family protein OMPH_PHOPR } \\
\text { porin-like protein } \mathrm{H}\end{array}$ & - & COG2199T \\
\hline W1_2114 & precursor & - & COG3203M \\
\hline W1_2115 & hypothetical protein W1_2115 & - & COG3110S \\
\hline W1_2158 & methyl-accepting chemotaxis protein & - & COG0840NT \\
\hline W1_2183 & hypothetical protein W1_2183 & - & COG2378K \\
\hline W1_2184 & ATPase involved in DNA repair & - & COG0419L \\
\hline W1_2228 & GGDEF family protein & - & COG3706T \\
\hline W1_2321 & GGDEF family protein & - & COG3614T \\
\hline W1_2326 & hypothetical protein W1_2326 & - & - \\
\hline W1_2327 & hypothetical protein W1_2327 & - & - \\
\hline W1_2329 & hypothetical protein W1_2329 & - & - \\
\hline W1_2330 & Flp pilus assembly protein $C p a B$ & - & COG3745U \\
\hline W1_2331 & Flp pilus assembly protein & - & COG4964U \\
\hline W1_2332 & hypothetical protein W1_2332 & - & - \\
\hline W1_2333 & $\begin{array}{l}\text { pilus assembly protein CpaE-like } \\
\text { protein }\end{array}$ & - & COG4963U \\
\hline W1_2334 & Flp pilus assembly protein & - & COG4962U \\
\hline W1_2335 & Flp pilus assembly protein TadB & - & COG4965U \\
\hline W1_2336 & Flp pilus assembly protein TadC & - & COG4965U \\
\hline W1_2337 & Flp pilus assembly protein TadD & - & COG5010U \\
\hline W1_2338 & hypothetical protein W1_2338 & - & - \\
\hline W1_2339 & hypothetical protein W1_2339 & - & COG4961U \\
\hline W1_2340 & hypothetical protein W1_2340 & - & - \\
\hline W1_2341 & azoreductase & $\mathrm{acpD}$ & COG11821 \\
\hline W1_2401 & super-integron integrase Int|A & - & COG4974L \\
\hline W1_2708 & hypothetical protein W1_2708 & - & - \\
\hline W1_2748 & response regulator & - & COG3437KT \\
\hline W1_2758 & amino acid transporter & - & - \\
\hline W1_2840 & $\begin{array}{l}\text { NhaP-type } \mathrm{Na}+/ \mathrm{H}+\text { and } \mathrm{K}+/ \mathrm{H}+ \\
\text { antiporters }\end{array}$ & - & COG0025P \\
\hline W1_2868 & methyl-accepting chemotaxis protein & - & COG0840NT \\
\hline W1_3144 & hypothetical protein W1_3144 & - & - \\
\hline W2_0019 & alcohol dehydrogenase & - & COG1454C \\
\hline W2_0073 & anti-anti-sigma regulatory factor & - & COG1366T \\
\hline
\end{tabular}

Table 2: Clade 2-specific genes (Continued)

\begin{tabular}{|c|c|c|c|}
\hline W2_0074 & anti-anti-sigma regulatory factor & - & COG1366T \\
\hline W2_0075 & anti-sigma regulatory factor & - & COG2172T \\
\hline W2_0076 & Serine phosphatase RsbU & - & - \\
\hline W2_0077 & FOG: CheY-like receiver & - & COG0642T \\
\hline W2_0078 & $\begin{array}{l}\text { response regulator AraC-type DNA- } \\
\text { binding domain-containing }\end{array}$ & - & COG3437KT \\
\hline W2_0212 & protein & - & COG2207K \\
\hline W2_0312 & hypothetical protein W2_0312 & - & - \\
\hline W2_0313 & response regulator & - & COG0745TK \\
\hline W2_0627 & $\begin{array}{l}\text { hypothetical protein W2_0627 AraC- } \\
\text { type DNA-binding domain-containing }\end{array}$ & - & COG2378K \\
\hline W2_0782 & protein & - & COG2207K \\
\hline W2_0783 & major facilitator superfamily permease & - & - \\
\hline W2_0851 & hypothetical protein W2_0851 & - & COG0845M \\
\hline W2_0864 & hypothetical protein W2_0864 & - & - \\
\hline W2_0868 & acetyltransferase & - & COG0456R \\
\hline W2_0881 & long-chain fatty acid $A B C$ transporter & - & COG2067I \\
\hline W2_0884 & $\mathrm{Mg} 2+$ and $\mathrm{Co} 2+$ transporter & - & - \\
\hline W2_0993 & transcriptional regulator & - & COG0583K \\
\hline W2_0994 & multidrug resistance efflux pump & - & COG1566V \\
\hline W2_1075 & dehydrogenase & - & COG1028IQR \\
\hline W2_1138 & hypothetical protein W2_1138 & - & COG3904S \\
\hline W2_1149 & hypothetical protein W2_1149 & - & - \\
\hline W2_1186 & transcriptional regulator & - & COG0583K \\
\hline W2_1203 & hypothetical protein W2_1203 & - & COG3930S \\
\hline W2_1204 & glutathione synthetase & - & COG0189HJ \\
\hline W2_1273 & transcriptional regulator & - & COG0583K \\
\hline W2_1274 & $\mathrm{Ca} 2+/ \mathrm{H}+$ antiporter & - & COG0387P \\
\hline W2_1275 & hypothetical protein W2_1275 & - & COG0586S \\
\hline W2_1290 & hypothetical protein W2_1290 & - & COG0834ET \\
\hline W2_1303 & hypothetical protein W2_1303 & - & - \\
\hline W2_1304 & Beta-glucosidase-related glycosidase & - & COG1472G \\
\hline W2_1309 & DMT family permease & - & - \\
\hline W2_1363 & transcriptional regulator & - & COG0583K \\
\hline
\end{tabular}

(VV2_1200, glucosamine-6-P deaminase) is in the $V$. vulnificus core genome, the clade 2 strains and 99-738 DP-B5 uniquely have the ability to assimilate exogenous sialic acid into central metabolism as fructose6-phosphate, relative to the other clade 1 strains and biotype 2 strains. However, $V$. vulnificus does not encode a neuraminidase (NanH) which would liberate sialic acid from host components. Almagro-Moreno and Boyd [41] had noted that sialic acid metabolism was unique to bacteria that interacted with mammalian hosts, either as pathogens or as commensals. Jeong et al. [42] recently constructed a nanA deletion in $V$. vulnificus and confirmed that the ability to utilize exogenous sialic acid was essential for virulence in intraperitoneally inoculated iron dextran-treated mice, as well as cytotoxicity in cell culture assays. They focused analysis of nanA on a single $V$. vulnificus 
Table 3 Genes common to V. vulnificus 99738 DP B5 and clade 2 strains

\begin{tabular}{|c|c|}
\hline Tag & Product \\
\hline W1_0251 & hypothetical protein W1_0251 \\
\hline W1_0411 & choline-glycine betaine transporter \\
\hline W1_0638 & $\begin{array}{l}\text { mannitol/fructose-specific } \\
\text { phosphotransferase system IIA protein }\end{array}$ \\
\hline W1_0639 & $\begin{array}{l}\text { mannitol-1-phosphate 5- } \\
\text { dehydrogenase }\end{array}$ \\
\hline W1_0640 & mannitol repressor protein \\
\hline W1_0641 & $\begin{array}{l}\text { D-fructose-6-phosphate } \\
\text { amidotransferase }\end{array}$ \\
\hline W1_0834 & DMT family permease \\
\hline W1_0835 & hypothetical protein W1_0835 \\
\hline W1_1655 & $\mathrm{H}+$ /gluconate symporter \\
\hline W1_1656 & sugar diacid utilization regulator \\
\hline W1_2188 & helicase-related protein \\
\hline W1_2189 & $\begin{array}{l}\text { tellurite resistance protein-related } \\
\text { protein }\end{array}$ \\
\hline W1_2744 & response regulator \\
\hline W1_2936 & putative transcriptional regulator \\
\hline W2_0151 & arylsulfatase A \\
\hline W2_0335 & methyl-accepting chemotaxis protein \\
\hline W2_0542 & manganese transporter NRAMP \\
\hline W2_0726 & hypothetical protein W2_0726 \\
\hline W2_0729 & transcriptional regulator \\
\hline W2_0730 & $\begin{array}{l}\text { dihydrodipicolinate synthase/ } \\
\text { Nacetylneuraminate lyase }\end{array}$ \\
\hline W2_0731 & $\begin{array}{l}\text { TRAP-type C4-dicarboxylate transport } \\
\text { System }\end{array}$ \\
\hline W2_0732 & $\begin{array}{l}\text { TRAP-type C4-dicarboxylate transport } \\
\text { system }\end{array}$ \\
\hline W2_0733 & $\begin{array}{l}\text { TRAP-type C4-dicarboxylate transport } \\
\text { system }\end{array}$ \\
\hline W2_0734 & $\begin{array}{l}\mathrm{N} \text {-acetylmannosamine-6-phosphate 2- } \\
\text { epimerase }\end{array}$ \\
\hline W2_0735 & $\mathrm{N}$-acetylmannosamine kinase \\
\hline W2_0736 & $\begin{array}{l}\mathrm{N} \text {-acetylglucosamine-6-phosphate } \\
\text { deacetylase }\end{array}$ \\
\hline W2_0892 & diadenosine tetraphosphate hydrolase \\
\hline W2_0893 & arsenite efflux pump ACR3 \\
\hline W2_0894 & transcriptional regulator \\
\hline W2_0920 & amidohydrolase \\
\hline W2_0988 & hypothetical protein W2_0988 \\
\hline W2_0989 & Alkyl sulfatase \\
\hline W2_1035 & $A B C$ transporter permease \\
\hline W2_1090 & hypothetical protein W2_1090 \\
\hline W2_1091 & hypothetical protein W2_1091 \\
\hline W2_1092 & hypothetical protein W2_1092 \\
\hline W2_1093 & $\begin{array}{l}\text { 2-deoxy-D-gluconate 3- } \\
\text { dehydrogenase }\end{array}$ \\
\hline W2_1094 & $\begin{array}{l}\text { galactose-1-phosphate } \\
\text { uridylyltransferase }\end{array}$ \\
\hline W2_1095 & UDP-glucose 4-epimerase \\
\hline W2_1096 & Sulfate permease \\
\hline W2_1097 & hypothetical protein W2_1097 \\
\hline
\end{tabular}

COG1593G

COG3090G

COG1638G

COG3010G

COG1940KG

COG1820G

COG0537FGR

COG0798P

COG0640K

COG0388R

COG20150

COG3932R

$$
-
$$

COG1028IQR

COG1085C

COG1087M

COG0659P
Table 3: Genes common to V. vulnificus 99738 DP B5 and clade 2 strains (Continued)

\begin{tabular}{|c|c|c|c|c|c|}
\hline Gene & $\operatorname{cog}$ & W2_1098 & CBS domain-containing protein & - & COG3448T \\
\hline - & COG3094S & W2_1099 & methyl-accepting chemotaxis protein & - & COG0840NT \\
\hline $\begin{array}{l}- \\
-\end{array}$ & $\begin{array}{l}\text { COG1292M } \\
\text { COG2213G }\end{array}$ & W2_1100 & $\begin{array}{l}\text { ATPase component of various ABC- } \\
\text { type transport system }\end{array}$ & - & COG1123R \\
\hline - & COG0246G & W2_1101 & $\begin{array}{l}\text { ABC-type dipeptide/oligopeptide/ } \\
\text { nickel transport system }\end{array}$ & - & DG1173EP \\
\hline$m t \mid R$ & COG3722K & W2_1102 & $\begin{array}{l}\text { ABC-type dipeptide/oligopeptide/ } \\
\text { nickel transport system }\end{array}$ & - & COG0601EP \\
\hline - & COG0449M & $\begin{array}{l}\text { W2_1104 } \\
\text { W2_1105 }\end{array}$ & $\begin{array}{l}\text { ABC-type dipeptide transport system } \\
\text { hypothetical protein W2_1105 }\end{array}$ & - & $\begin{array}{l}\text { COG0747E } \\
\text { COG4289S }\end{array}$ \\
\hline - & - & W2_1106 & arylsulfatase $\mathrm{A}$ & - & COG3119P \\
\hline- & - & W2_1107 & arylsulfatase regulator & - & COG0641R \\
\hline- & COG2610GE & W2_1108 & arylsulfatase $\mathrm{A}$ & - & COG3119P \\
\hline - & COG3835KT & W2_1109 & arylsulfatase $\mathrm{A}$ & - & COG3119P \\
\hline- & COG1061KL & W2_1110 & hypothetical protein W2_1110 & - & - \\
\hline- & $\mathrm{COG} 2227 \mathrm{H}$ & W2_1259 & hypothetical protein W2_1259 & - & - \\
\hline- & COG2197TK & $\begin{array}{l}\text { W2_1403 } \\
\text { W2_1505 }\end{array}$ & $\begin{array}{l}\text { GGDEF domain-containing protein } \\
\text { hypothetical protein W2_1505 }\end{array}$ & - & $\begin{array}{l}\text { COG2199T } \\
\text { COG1233Q }\end{array}$ \\
\hline - & COG3119P & W2_1508 & $\begin{array}{l}\text { putative two-component response } \\
\text { regulator }\end{array}$ & - & COG2197TK \\
\hline- & COG0840NT & W2_1509 & GGDEF family protein & - & COG2199T \\
\hline - & COG1914P & W2_1510 & response regulator & - & COG2197TK \\
\hline- & COG3055S & W2_1511 & response regulator VieA & - & COG2200T \\
\hline- & COG1737K & W2_1512 & sensor kinase VieS & - & COG0642T \\
\hline
\end{tabular}

strain and did not perform comparative genetics among strains of different genotypes or virulence phenotypes. The summation of these data regarding nanA is that our comparative genomic sequencing correctly identified unique virulence genes among different sets of $V$. vulnificus.

Another carbon source utilization pathway specific to the clade 2 plus 99-738 DP-B5 strains but not in genomic island XII is a complete mannitol catabolic pathway encoding the mannitol/fructose-specific phosphotransferase system IIA protein (mtlABC, VV1_0638), mannitol-1specific mannitol repressor ( $m t l R$, VV1_0640). The significance of these genes to virulence is unknown. Interestingly, by examining $465 \mathrm{~V}$. vulnificus strains, Drake et al. [22] previously determined that the ability to ferment mannitol by $V$. vulnificus was highly correlated with a strain being in, what we are calling, clade 2 . Tison et al. [14] reported that biotype 2 strains were mannitolnegative. Our sequencing data, albeit on a considerably smaller sample size of strains, therefore corroborate the phenotypic analyses of these two previous studies.

\section{SNP analysis}

In addition to the presence or absence of whole genes or blocks of genes, detailed above, genetic variation among the sequenced strains also consisted of nucleotide phosphate 5-dehydrogenase ( $\left.m t l D, \mathrm{VV} 1 \_0639\right)$, and a 
polymorphisms. We used MAQ to identify SNPs present in the newly sequenced genomes relative to the reference genomes. The SNPs from each of the pairwise analyses versus the reference genomes are listed in Additional Files $6,7,8,9,10,11,12$, and 13 , and the summary of the numbers of SNPs from each sequenced strain relative to the reference genomes is shown in Table 4. In examining SNPs, we did not exclude any sets of genes, such as putative mobile genetic elements, e.g., phages. It is interesting that M06-24/O, which had the highest amount of coverage relative to the reference genomes, had the lowest number of SNPs (mean of 42,191 SNPs per reference genome) compared with the other three strains (mean of 73,130 SNPs per reference genome). This likely reflects the fact that M06-24/O is in the same clade as the reference genomes.

The accuracy of the SOLiD-based SNPs in identifying polymorphisms was verified by examining Sanger sequencing of specific genomic regions of each of these strains. Having examined $8.7 \mathrm{~kb}$ of Sanger-derived sequence that contained SNPs identified from our SOLiD sequencing, we determined that 126 of 128 SNPs were accurately identified (98.4\% accuracy).

We then examined the distribution of nonredundant SNPs among different sets of annotated ORFs using the CMCP6 reference genome. It must be emphasized that the vast majority of annotated ORFs have not been experimentally verified; hence, such an analysis is conjectural. Of the 201,981 nonredundant SNPs in the CMCP6 genome from all four sequenced strains, 177,464 fell within annotated ORFs (87.9\%). This was not unexpected since this figure approximates the amount of the genome contained within annotated ORFs [30]. However, other interesting trends were evident. There were highly significant differences in the frequencies of SNPs between chromosomes 1 and 2 of CMCP6. Among the annotated ORFs, there were 0.037 SNPs/base for chromosome 1 and 0.044 SNPs/base in chromosome 2. Among the other sets of ORFs, there were significantly more SNPs/base in the core genome (0.043 SNPs/base) than in the total ORFs (0.040 SNPs/ base) (Figure 2). As opposed to the inference that the core genome is actually more variable among strains, this difference most likely is due to the fact that the core genome, by definition, was shared among all of the sequenced strains; hence, had more shared sequences in which SNPs could be identified. In contrast, the lowest rate of SNPs was among the clade 2-specific genes, with only 0.019 SNPs/base. In the opposite manner to the core genome, this result would be expected since the clade 2-specific genes are unique and shared among the set of three genetically related clade 2 strains and because only one newly sequenced clade 2 strain, M06-
24/O, contributed to this particular SNP pool. The frequency of SNPs in the clade $2+99-738$ DP-B5 set of ORFs was $0.033 \mathrm{SNPs} / \mathrm{base}$. The frequency of SNPs among hypothetical proteins (0.037 SNPs/base) was significantly lower than that of the total ORFs.

\section{Lineage-specific Expansions}

$\mathrm{Gu}$ et al. [43]. recently reported an analysis of numerous Vibrio spp. to identify lineage-specific expansions (LSEs), genes that have been duplicated within a species or genotype. Some LSEs are specific to single strain, while others are present among varied strains across species. We examined some of the LSEs present in the reference genomes of $V$. vulnificus to determine if these loci are similarly present in the newly sequenced $V$. vulnificus genomes. We did not find a pattern to the presence or absence of the LSEs examined. For example, VV1_3196 and VV2_0703 form a pair of LSE genes in CMCP6. Neither of these genes has a homologue in YJ016 or any of the newly sequenced $V$. vulnificus genomes. In contrast, VV1_2851 and VV2_0347 constitute a pair of LSEs in CMCP6 that have homologues in YJ106 (VV1419 and VVA0904). The VV1_2851/VV1419 pair of genes has homologues in all of the four newly sequenced genomes, while VV2_0347 and VVA0904 do not.

\section{Discussion}

This study is one of the first to use Applied Biosystems SOLiD sequencing for genomic sequencing of bacteria. Whole genome analysis has progressed considerably since the publication of the first complete DNA sequence of the pathogenic bacterium Haemophilus influenzae [44]. Until recently, the wealth of complete genomes available in public databases was decoded via the largescale industrialization of the Sanger dideoxy chain-termination sequencing method $[45,46]$. The prospect of quickly and inexpensively resequencing large segments of the human genome or whole genomes of populations or species is driving development of a new generation of sequencing technologies with impacts in microbiology, functional genomics, ecology and evolutionary biology, human health, and beyond [45,47-51]. In particular, bacterial sequencing has been advanced by the high throughput, parallel format of the 454 Sequencer [51], the first 'next-generation' technology to de novo sequence and assemble whole bacterial genomes including Mycoplasma genitalium in a single machine run [52]. Bacterial comparative genomics has expanded rapidly owing to the speed of the 454 Sequencer compared to Sanger sequencing [53] as well as from a combination of the two technologies [54], while assessment of microbial diversity from complex communities (metagenomics) [55] has revealed insights into complex interactions such as 
Table 4 Numbers of SNPs from each of the four sequenced genomes relative to the two chromosomes of the reference genomes

\begin{tabular}{lcccccc}
\hline & \multicolumn{3}{c}{ CMCP6 } & & YJ016 \\
\cline { 2 - 7 } & Chrom. 1 & Chrom. 2 & Total & Chrom. 1 & Chrom. 2 & Total \\
\hline M06-24/O & 23,752 & 17,390 & 41,142 & 25,530 & 17,709 & 43,239 \\
99-738 DP-B5 & 46,469 & 27,457 & 73,926 & 46,833 & 27,152 & 73,985 \\
99-520 DP-B8 & 46,059 & 26,440 & 72,499 & 46,156 & 26,223 & 72,379 \\
ATCC 33149 & 46,259 & 26,355 & 72,614 & 47,549 & 25,828 & 73,377 \\
\hline
\end{tabular}

mammalian obesity and the microbiome [56,57], the ocean biosphere [58], and the role of microbes in colony collapse disorder in honeybees [59].

More recently released 'second-generation' sequencing technologies such the Illumina GA2X Genome Analyzer (GA) and ABI SOLiD system have been developed [51]. To date, these next generation sequencing technologies generate shorter read lengths than Sanger sequencing, which poses a difficulty for de novo sequence assembly and defining large chromosomal rearrangements [49,51]. So far in prokaryotes, high quality draft sequences have been assembled in the absence of Sanger sequencing by combing the 454 and GA technologies [60-64]. Studholme et al. [65] utilized the Illumina platform alone for the de novo assembly of the draft genome sequence of Pseudomonas syringae pathovar tabaci strain 11528, revealing insights into the nature of type III proteinmediated pathogenicity.

The improved throughput from the massively parallel format of the new platforms (billions of bases in a single run) is ideal for revealing patterns of genetic variation among individuals by resequencing. For example, Srivatsan et al. [66] employed Illumina sequencing to improve the existing draft of the extensively studied model bacterium Bacillus subtilis, while also identifying polymorphisms between other well studied laboratory strains and their isolates. Moreover, this method was sensitive enough to identify typically difficult to isolate suppressor mutations in a single strain [66]. Using the same platform, whole-genome analysis of 12 isolates of the monomorphic human pathogen Salmonella enterica serovar Typhi revealed evolutionary loss of gene function consistent with the effects of genetic drift on a small effective population size [67]. Resequencing of the Caernohabditis elegans N2 Bristol strain and SNP discovery in another strain demonstrated the effectiveness of this technology in eukaryotes [68], and single base mutations in a mutant $C$. elegans strain were mapped, avoiding traditional genetic mapping efforts [69].

As one of the newer second-generation sequencers currently available, (although 'third-generation' single molecule sequencers are set to be marketed in 2010), the ABI SOLiD platform has been used more with eukaryotes than prokaryotes. One of the first studies focused on assessing cross-platform performance for sequence detection of known mutations in C. elegans. Comparable accuracy between GA and SOLiD for mapping the same $C$. elegans mutant strain as Sarin et al. [69] was reported [70]. Similarly, comparable accuracy was reported between 454, GA, and SOLiD methods for comparing a mutant strain of yeast to a reference genome [71]. At present the utility of the SOLiD platform is reflected in several resequencing studies in humans, including haplotype analysis, breakpoint mapping in disease-associated chromosomal rearrangements, and polymorphism discovery in protein coding exons [72-74]. With bacteria, SOLiD sequencing has been limited to verifying an $E$. coli reference strain sequence in conjunction with traditional sequencing [75], as well as resequencing of Bacillus anthracis strains for rapid and accurate forensic typing [76]. In our presently described study, the SOLiD platform was successfully utilized for rapid comparative genomic analysis of clade-specific and core genome sequences of the opportunistic pathogen V. vulnificus.

By examining the genomic DNA of each of four $V$. vulnificus strains on one-fourth of a SOLiD slide, we obtained $3.16 \times 10^{7}$ to $3.50 \times 10^{7} 35$-nt reads. This level of sequencing yielded approximately 100 -fold coverage of each genome. Although the total numbers of reads would have predicted over 200 -fold coverage, there was a significant amount of low complexity reads, as well as reads that were unmappable to the reference genomes.

We identified sequences that are unique to the highly virulent clade 2 strains. These 80 genes represent the set that could contain virulence genes that are responsible for the ability of clade 2 strains to cause systemic infection and death in subcutaneously inoculated iron dextran-treated mice (Thiaville, P.C., et al., Infect. Immun. submitted). Furthermore, we identified 61 additional genes that are common to the clade 2 strains and an unusual highly virulent clade 1 strain but absent from a typical attenuated clade 1 strain and a biotype 2 eel isolate. These 61 genes represent a very interesting set that could contain generally clade 2 -specific genes that were acquired by a clade 1 strain and increased its virulence to that of typical clade 2 strains. Among these putative virulence genes were genomic island XII 


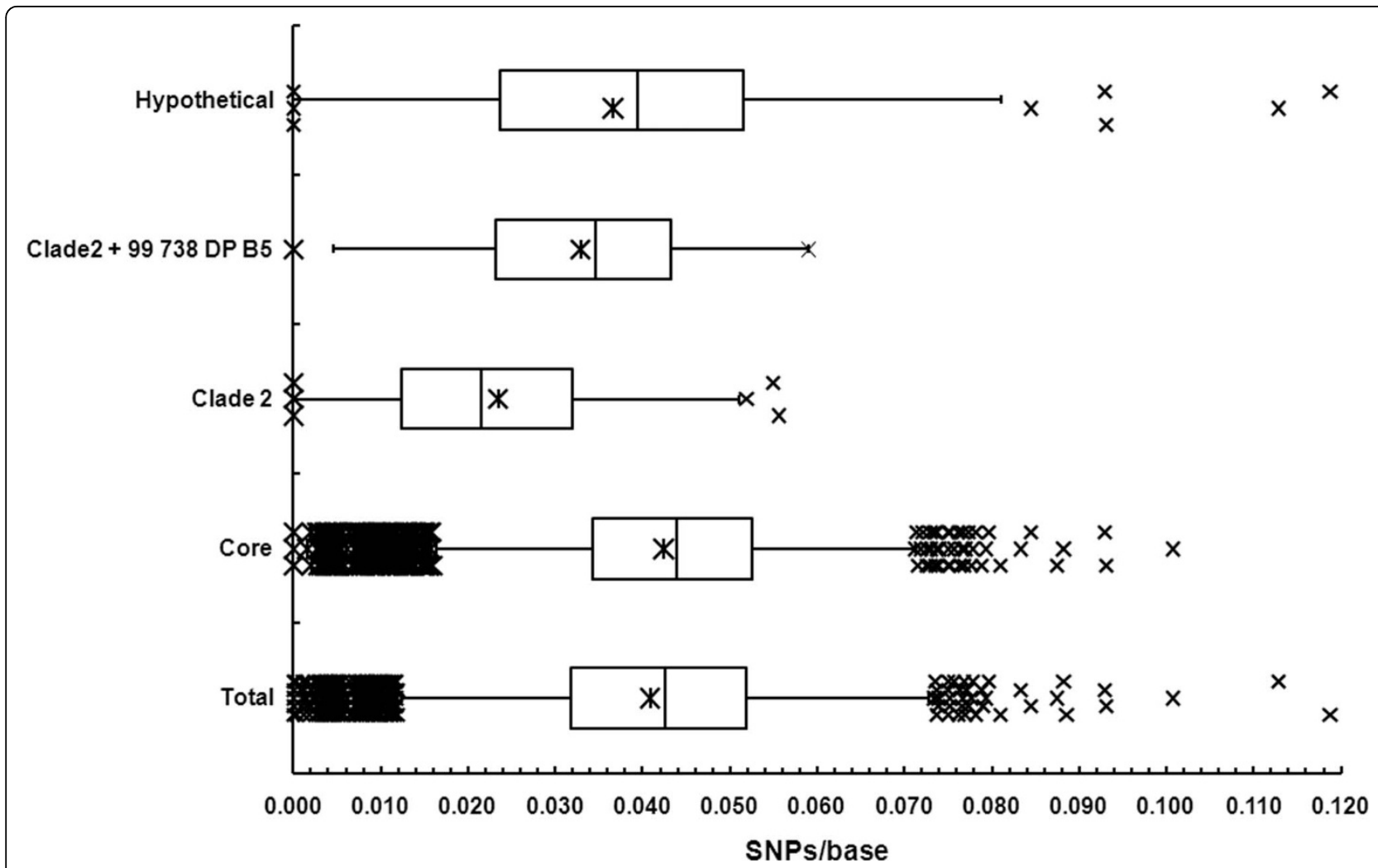

Figure 2 Distribution of SNPs Relative to the CMCP6 Genome and Subsets of Genes. Box and whisker plots of the SNPs/base for each of the subsets of annotated genes are shown.

identified by Cohen et al. [20], and most interesting was a set of genes involved with sialic acid catabolism. Jeong et al. [42] recently determined that the ability to utilize sialic acid for metabolism was essential for virulence of V. vulnificus. We are currently examining the possible roles of several of these loci in virulence.

At the time of our performing this genomic sequence analysis, we had not performed virulence studies of biotype 2 ATCC 33149 in our subcutaneously inoculated iron dextran-treated mouse model for infection. However, Amaro et al. [77] previously reported that ATCC 33149 was of modest virulence in a different mouse model involving intraperitoneal infection. Based on our results indicating that ATCC 33149 lacked the genes shared among virulent clade 2 strains or clade 2 strains plus virulent clade 1 99-738 DP-B5, we hypothesized that ATCC 33149 would be attenuated for virulence in our model. In fact, when administered at the standard lethal dose of 1,000 CFU for virulent strains, ATCC 33149 caused only minimally detectable skin infection in one of five mice. Furthermore, when administered at 100 times the typical lethal dose $\left(10^{5} \mathrm{CFU} /\right.$ mouse $)$, skin infection but no systemic infection or death ensued. Therefore, our genomic analysis of ATCC 33149 correctly predicted its attenuated virulence. It should be noted that Amaro and Biosca [78] reported that some biotype 2 strains are virulent for mammals, so the attenuation of ATCC 33149 was not a foregone conclusion.

Because phenotypic differences are not only rooted in presence or absence of whole genes, but also nucleotide polymorphisms, we generated a set of SNPs among the shared sequences of the reference and newly sequenced genomes (Table 4 and Additional Files 6, 7, 8, 9, 10, 11, 12 , and 13). By examining Sanger-derived sequences for a subset of SNPs, we determined that $98.4 \%$ of our reported SNPs are accurate. Of the 128 SNPs examined, only two in one gene of one strain were not confirmed by Sanger sequencing.

Although the sample size of newly sequenced strains was small and each strain is a single representative of a unique genotype/virulence phenotype combination, some interesting relationships in SNPs were observed. Most interesting, the rate of SNPs was significantly higher for genes encoded on chromosome 2 compared with chromosome 1. Given that chromosome 1 of Vibrio is believed to encode most of the essential genes and that chromosome 2 is believed to have been acquired exogenously [79], it is reasonable that the 
highest rate of polymorphisms would occur in the chromosome 2. The number of SNPs between M06-24/O and the reference genomes was much lower than those from the other three genomes (Table 4), even though there were slightly more genes identified in M06-24/O. Because M06-24/O is in the same clade as the reference genomes, this result would be expected. Significant differences were observed in the frequencies of SNPs among about every subset of genes examined, e.g., clade 2-specific, core genome, hypothetical proteins (Figure 2). However, it must be noted that the numbers of strains contributing to the SNP pool for these subsets of genes differ between the sets. For example, the core genome is shared among all six strains, so all four newly sequenced strains contributed SNPs and could have generated a higher frequency of SNPs. In contrast, for the clade 2-specific genes, the only newly sequenced strain contributing SNPs, by definition of the subset, was M06-24/O.

By comparing the sequences shared among all six genomes, we identified the core $V$. vulnificus genome consisting of 3,459 genes. Gu et al. [43] examined the genomic sequences of all Vibrio species as of 2008 and identified 1,882 genes common to the genus. We are presently examining the core $V$. vulnificus genome to deduce possible metabolic and virulence characteristics of the species. We identified 20 genes previously unreported in V. vulnificus by using MAQ to compare the unmapped reads to the $V$. cholerae N16961 genome. If the clade 1 or biotype 2 genomes possessed sequences with sufficient similarity to the $V$. cholerae genome, we should have been able to identify and assemble them exactly as we did for the $V$. vulnificus reference genomes.

Most recently, Chun et al. [80] examined the genomes of $23 \mathrm{~V}$. cholerae strains collected over 98 years. Their newly sequences genomes were obtained using a combination of Sanger and 454 sequencing. Like us, they based their phylogenetic relationships primarily on presence or absence of ORFs. Their analysis enabled the division of that species into 12 lineages, with one comprising the $\mathrm{O} 1$ strains and the seventh pandemic comprising a nearly identical clade. They determined that horizontal gene transfer significantly contributed to the evolution of the species.

\section{Conclusions}

SOLiD sequencing of multiple bacterial genomes of V. vulnificus and subsequent comparative genomic analysis identified numerous genes that are common to the most virulent strains yet lacking from attenuated strains for which genomic DNA sequence data are available. These candidate virulence genes encode Flp pili, GGDEF proteins, and genomic island XII. Sialic acid catabolism was similarly identified as a potential contributory factor in molecular pathogenesis. These intriguing results will likely lead to more thorough understanding of molecular pathogenesis of $V$. vulnificus.

\section{Methods}

\section{V. vulnificus strains}

Each of the four $V$. vulnificus strains used for genomic sequencing was chosen to represent a specific combination of genotype and virulence phenotype. M06-24/O is a typical biotype 1 , clade 2 strain that is highly virulent in our subcutaneously inoculated, iron dextran-treated mouse model. 99-520 DP-B8 is a typical biotype 1, clade 1 strain that is attenuated in our mouse model in that it can cause skin infection, but not systemic infection or death. 99-738 DP-B5 is an unusual biotype 1, clade 1 strain in that it is fully virulent in our mouse model. ATCC 33149 is a biotype 2 strain that is highly attenuated for virulence in our mouse model. These data are summarized in Table 1.

\section{SOLiD DNA sequencing}

Sequencing runs were done using cycled ligation sequencing on a SOLiD ${ }^{\mathrm{rm}}$ Analyzer (Applied Biosystems, Beverly, MA) at the Interdisciplinary Center for Biotechnology Research at the University of Florida. Approximately 3 to $5 \mu \mathrm{g}$ of purified bacterial genomic DNA was sheared into 80 to 100 -bp short fragments with the Covaris ${ }^{\mathrm{TM}} \mathrm{S} 2$ system according to the AB protocol. The sheared DNA was purified using a Qiagen MiniElute ${ }^{\bullet}$ reaction cleanup kit. The purified sheared fragments were made blunt-ended with the Epicenter ${ }^{\odot}$ End-It ${ }^{\mathrm{TM}}$ DNA end-repair kit and subsequently ligated to short SOLiD P1 and P2 adapters (P1, 41-bp: 5'-CCACTACGCCTCCGCTTTCCTCTCTATGGGCAGTCGGTGAT-3'; P2, 23-bp: 5'-AGAGAATGAGGAACCCGGGGCAG-3'), which provide the primary sequences for both amplification and sequencing of the sample library fragments. Adapter-ligated DNA was then purified using the Agencourt kit. The reaction conditions were optimized to selectively bind DNA 100-bp and larger. At this point, DNA was nick-translated and resolved on $4 \%$ agarose gel, from which the 120 to 180 -bp fragments were excised. The fractionated DNA was subjected to 8 to 10 cycles of PCR amplification. The number of PCR cycles needed for amplification was determined by the ability to visualize the amplified product on a $2.2 \%$ Lonza flash gel. The amplified PCR products were purified and then quantified using an Agilent 2100 bioanalyzer.

In preparation for sequencing, the DNA fragments were clonally amplified by emulsion PCR by using 1.6 billion, $1 \mu \mathrm{M}$ beads with P1 primer covalently attached to the surface. Emulsions were broken with butanol, and ePCR beads were enriched for template-positive beads by hybridization with P2-coated capture beads (SOLiD reagent, Applied Biosystems). Template-enriched beads 
were extended at the 3 ' end in the presence of terminal transferase and 3' bead linker. About 60 million beads with clonally amplified DNA were then deposited onto one-fourth of a derivatized glass surface of a $25 \mathrm{~mm} \times$ $75 \mathrm{~mm} \mathrm{SOLiD}^{\mathrm{m}}$ slide. The slide was then loaded onto a SOLiD instrument, and the 35-base sequences were obtained according to manufacturer's protocol.

\section{DNA sequence data management}

The colorspace reads from SOLiD sequencing were aligned to the genomes of $V$. vulnificus strains CMCP6 (GenBank accession numbers AE016795 and AE016796) and YJ016 (GenBank accession numbers BA000037, BA000037, AP005352) using MAQ [27]. Reads from each of the four sample strains were mapped to the two reference sequences separately. Reads unmapped in both reference genomes were identified. Mapped reads were used to develop a consensus sequence for each of the four strains. For each strain relative to the two reference sequences, a gene was determined to be absent when the average depth of coverage over the open reading frame was less than $5 \mathrm{X}$. Consensus sequences were also used to generate a list of SNPs among the six strains of $V$. vulnificus using the MAQ cns2snp [27].

Reads with low-complexity characteristics, defined as containing a homopolymer run of at least 5 bases, at least four repeats of the same dinucleotide in a row, or at least four repeats of the same trinucleotide in a row, were removed from the data set before further analysis. While these reads may represent true genomic regions, the difficulty in assigning them to a particular genomic region limits their value. This is an inherent problem with low complexity genomes and short read data. Reads unmapped in both reference sequences were then compared to the $V$. cholerae NC16961 reference genome using MAQ [27]. Windows of 100 nucleotides in the $V$. cholerae genome with a read depth of five or more were identified. Regions where five or more windows occurred in tandem were retained, while those with coverage less than five were discarded. Reads that initially mapped to a lower density area of the $V$. cholerae genome were re-examined for possible matches to the tandem windows.

In parallel to the $V$. cholerae exploration, the unmapped reads were examined for similarity to $V$. vulnificus biotype 2 plasmids pR99 (accession \# AM293858), pC4602-1 (accession \# AM293859), and pC4602-2 (accession \# AM293860) using MAQ and the same criteria as above.

\section{Bioinformatic alnalysis}

Functional analysis and annotations analysis of the V. vulnificus YJ016 and CMCP6 genes were done using the Pathway Tool Omics viewer from the BioCyc platform [81] and the SEED database [82].

\section{Additional material}

Additional file 1: Table S1: Coverage of the V. vulnificus biotype 2 plasmids by newly sequenced reads. SOLiD sequencing reads of each of the four newly sequenced genomes were matched with the three plasmids of $V$. vulnificus biotype 2 using MAQ. The size of each plasmid is shown. *Numbers of nucleotides of the reference plasmid with less than 10 -fold coverage by 35 -nt reads from the newly sequenced genome. **Number of nucleotides that were matched by virtue of having 10-fold or greater coverage depth. ${ }^{* *}$ Percent of reference plasmid matched to the newly sequenced genome.

Additional file 2: Table S2: Identification of ORFs in newly sequenced $V$. vulnificus genomes by matching with the $V$. cholerae NC16961 genome. SOLiD sequencing reads of each of the four newly sequenced genomes were matched with the V. cholerae NC16961 using MAQ, as described in the Methods. V. vulnificus strains: M06 - M06-24/O, B5 - 99-738 DP-B5, B8 - 99-520 DP-B8, ATCC - ATCC 33149. Genes were considered matched if there was five-fold or higher depth of coverage over five tandem 100-nt windows.

Additional file 3: Table S3A: Matches of CMCP6 genes from the YJ016 reference genome and the four newly sequenced genomes. The CMCP6 genes are shown by their tag, gene name (if annotated), and product (if known). Matching of each gene with the newly sequenced genomes was determined using MAQ, as described in the Methods. Matches with the YJ016 genome were obtained using GenPlot at http:// www.ncbi.nlm.nih.gov using default parameters. Genes from each queried genome that were not matched to the CMCP6 genome are indicated with an X. If a CMCP6 gene is missing from all of the other five genomes, it is indicated with an $\times$ in the CMCP6-Specific column. $V$. vulnificus strains: M06 - M06-24/O, B5 - 99-738 DP-B5, B8 - 99-520 DP-B8, ATCC - ATCC 33149.

Additional file 4: Table S3B: Matches of YJ016 genes from the CMCP6 reference genome and the four newly sequenced genomes. The YJ016 genes are shown by their tag, gene name (if annotated), and product (if known). Matching of each gene with the newly sequenced genomes was determined using MAQ, as described in the Methods. Matches with the CMCP6 genome were obtained using GenPlot at http://www.ncbi.nlm.nih.gov using default parameters. Genes from each queried genome that were not matched to the YJ016 genome are indicated with an X. If a YJ016 gene is missing from all of the other five genomes, it is indicated with an $\times$ in the YJ016-Specific column. $V$. vulnificus strains: M06 - M06-24/O, B5 - 99-738 DP-B5, B8 - 99-520 DP-B8, ATCC - ATCC 33149.

Additional file 5: Table S4: The core $V$. vulnificus genome. Genes that were present in the two reference genomes and each of the four newly sequenced genomes are shown using the CMCP6 tag, product, gene name, and cog.

Additional file 6: Table S5A: SNP analysis of $V$. vulnificus M06-24/O compared with the CMCP6 reference genomes. MAQ was used to identify SNPs from the SOLiD sequencing reads from M06-24/O compared with the CMCP6 reference genome, as described in the Methods. Pos. - Position of the nucleotide in the genomic element. Ref. Reference base in the reference genome. Con. - Consensus base in the newly sequenced genome. Con. QS - Consensus Quality Score. Read depth - Depth of coverage at the chosen nucleotide. Avg. hits - Average number of hits of reads covering the position. HMQ - Highest mapping quality of reads covering the position. MCQ - Minimum consensus quality in the third flanking region on each side of the site. 2nd - second best call for the nucleotide. LLR - Log likelihood ratio of the second and third best call. 3rd - Third best call.

Additional file 7: Table S5B: SNP analysis of $V$. vulnificus M06-24/O compared with the YJ016 reference genome. MAQ was used to identify SNPS from the SOLiD sequencing reads from M06-24/O compared with the YJ016 reference genome, as described in the Methods. Column headings are as for Additional File 6, Table S5A.

Additional file 8: Table S6A: SNP analysis of $V$. vulnificus 99-738 DPB5 compared with the CMCP6 reference genome. MAQ was used to identify SNPs from the SOLiD sequencing reads from 99-738 DP-B5 
compared with the CMCP6 reference genome, as described in the Methods. Column headings are as for Additional File 6, Table S5A.

Additional file 9: Table S6B: SNP analysis of $V$. vulnificus 99-738 DPB5 compared with the YJ016 reference genome. MAQ was used to identify SNPs from the SOLiD sequencing reads from 99-738 DP-B5 compared with the YJ016 reference genome, as described in the Methods. Column headings are as for Additional File 6, Table S5A

Additional file 10: Table S7A: SNP analysis of $V$. vulnificus 99-520 DP-B8 compared with the CMCP6 reference genome. MAQ was used to identify SNPs from the SOLiD sequencing reads from 99-520 DP-B8 compared with the CMCP6 reference genome, as described in the Methods. Column headings are as for Additional File 6, Table S5A.

Additional file 11: Table 7B: SNP analysis of $V$. vulnificus 99-520 DPB8 compared with the YJ016 reference genome. MAQ was used to identify SNPs from the SOLiD sequencing reads from 99-520 DP-B8 compared with the YJ016 reference genome, as described in the Methods. Column headings are as for Additional File 6, Table S5A.

\section{Additional file 12: Table 8A: SNP analysis of $V$. vulnificus ATCC} 33149 compared with the CMCP6 reference genome. MAQ was used to identify SNPs from the SOLiD sequencing reads from ATCC 33149 compared with the CMCP6 reference genome, as described in the Methods. Column headings are as for Additional File 6, Table S5A.

\section{Additional file 13: Table 8B: SNP analysis of $V$. vulnificus ATCC} 33149 compared with the YJ016 reference genome. MAQ was used to identify SNPs from the SOLiD sequencing reads from ATCC 33149 compared with the YJ016 reference genome, as described in the Methods. Column headings are as for Additional File 6, Table S5A.

\section{Acknowledgements}

We thank Robert Edwards for the initial BLAST analysis of the SOLiD sequencing data. We thank Patrick Thiaville for critical review of this manuscript.

This work was supported by funding from the University of Florida Emerging Pathogens Institute, The University of Florida Opportunity Fund, and Florida Sea Grant. Publication of this article was funded in part by the University of Florida Open-Access Publishing Fund.

\section{Author details}

${ }^{1}$ Department of Molecular Genetics and Microbiology, University of Florida, Gainesville, Florida, USA. ²Department of Microbiology and Cell Science, University of Florida, Gainesville, Florida, USA. ${ }^{3}$ Department of Food Science and Human Nutrition, University of Florida, Gainesville, Florida, USA. ${ }^{4}$ Department of Genetics, University of Melbourne, 3010 Australia.

\section{Authors' contributions}

PAG planned and coordinated the research, analyzed data, and wrote the manuscript. VDC contributed to data analysis and writing. ACW contributed to planning and writing. BW performed MAQ data analysis and planning. MTS contributed to the writing the manuscript. LMM helped plan the study, planned analyses, and contributed to the writing of the manuscript. All authors read and approved the final manuscript.

Received: 15 March 2010 Accepted: 24 September 2010 Published: 24 September 2010

\section{References}

1. Gulig PA, Bourdage KL, Starks AM: Molecular Pathogenesis of Vibrio vulnificus. J Microbiol 2005, 43:118-131.

2. Oliver JD, Jones MK: Vibrio vulnificus: Disease and pathogenesis. Infect Immun 2009, 77:1723-1733.

3. Simpson LM, White VK, Zane SF, Oliver JD: Correlation between virulence and colony morphology in Vibrio vulnificus. Infect Immun 1987, 55:269-272.

4. Wright AC, Simpson LM, Oliver JD, Morris JG Jr: Phenotypic evaluation of acapsular transposon mutants of Vibrio vulnificus. Infect Immun 1990, 58:1769-1773.
5. Liu M, Alice AF, Naka H, Crosa JH: The HlyU protein is a positive regulator of $r t x A 1$, a gene responsible for cytotoxicity and virulence in the human pathogen Vibrio vulnificus. Infect Immun 2007, 75 . 3282-3289.

6. Lee JH, Kim MW, Kim BS, Kim SM, Lee BC, Kim TS, Choi SH: Identification and characterization of the Vibrio vulnificus rtxA essential for cytotoxicity in vitro and virulence in mice. J Microbiol 2007, 45:146-152.

7. Kim YR, Lee SE, Kook H, Yeom JA, Na HS, Kim SY, Chung SS, Choy HE, Rhee JH: Vibrio vulnificus RTX toxin kills host cells only after contact of the bacteria with host cells. Cell Microbiol 2008, 10:848-862.

8. Litwin CM, Rayback TW, Skinner J: Role of catechol siderophore synthesis in Vibrio vulnificus virulence. Infect Immun 1996, 64:2834-2838.

9. Wright AC, Simpson LM, Oliver JD: Role of iron in the pathogenesis of Vibrio vulnificus infections. Infect Immun 1981, 34:503-507.

10. Paranjpye RN, Strom MS: A Vibrio vulnificus type IV pilin contributes to biofilm formation, adherence to epithelial cells, and virulence. Infect Immun 2005, 73:1411-1422.

11. Paranjpye RN, Lara JC, Pepe JC, Pepe CM, Strom MS: The type IV leader peptidase/ $\mathrm{N}$-methyltransferase of Vibrio vulnificus controls factors required for adherence to HEp-2 cells and virulence in iron-overloaded mice. Infect Immun 1998, 66:5659-5668.

12. Kim YR, Rhee JH: Flagellar basal body flg operon as a virulence determinant of Vibrio vulnificus. Biochem Biophys Res Commun 2003, 304:405-410.

13. Lee JH, Rho JB, Park KJ, Kim CB, Han YS, Choi SH, Lee KH, Park SJ: Role of flagellum and motility in pathogenesis of Vibrio vulnificus. Infect Immun 2004, 72:4905-4910.

14. Tison DL, Nishibuchi M, Greenwood JD, Seidler RJ: Vibrio vulnificus biogroup 2:new biogroup pathogenic for eels. Appl Environ Microbiol 1982, 44:640-646.

15. Bisharat N, Agmon V, Finkelstein R, Raz R, Ben Dror G, Lerner L, Soboh S, Colodner R, Cameron DN, Wykstra DL, Swerdlow DL, Farmer JJ Jr: Clinical, epidemiological, and microbiological features of Vibrio vulnificus biogroup 3 causing outbreaks of wound infection and bacteraemia in Israel. Israel Vibrio Study Group. Lancet 1999, 354:1421-1424.

16. Nilsson WB, Paranjpye RN, DePaola A, Strom MS: Sequence polymorphism of the $16 \mathrm{~S}$ rRNA gene of Vibrio vulnificus is a possible indicator of strain virulence. J Clin Microbiol 2003, 41:442-446.

17. Gonzalez-Escalona N, Jaykus LA, DePaola A: Typing of Vibrio vulnificus strains by variability in their 16S-23 S rRNA intergenic spacer regions. Foodborne Pathog Dis 2007, 4:327-337.

18. Bisharat N, Cohen DI, Harding RM, Falush D, Crook DW, Peto T, Maiden MC: Hybrid Vibrio vulnificus. Emerg Infect Dis 2005, 11:30-35.

19. Bisharat N, Cohen DI, Maiden MC, Crook DW, Peto T, Harding RM: The evolution of genetic structure in the marine pathogen, Vibrio vulnificus. Infect Genet Evol 2007, 7:685-693.

20. Cohen AL, Oliver JD, DePaola A, Feil EJ, Boyd EF: Emergence of a virulent clade of Vibrio vulnificus and correlation with the presence of a 33kilobase genomic island. Appl Environ Microbiol 2007, 73:5553-5565.

21. Rosche TM, Yano Y, Oliver JD: A rapid and simple PCR analysis indicates there are two subgroups of Vibrio vulnificus which correlate with clinical or environmental isolation. Microbiol Immunol 2005, 49:381-389.

22. Drake SL, Whitney B, Levine JF, DePaola A, Jaykus LA: Correlation of mannitol fermentation with virulence-associated genotypic characteristics in Vibrio vulnificus isolates from oysters and water samples in the Gulf of Mexico. Foodborne Pathog Dis 2010, 7:97-101.

23. Starks AM, Schoeb TR, Tamplin ML, Parveen S, Doyle TJ, Bomeisl PE, Escudero GM, Gulig PA: Pathogenesis of infection by clinical and environmental strains of Vibrio vulnificus in iron dextran-treated mice. Infect Immun 2000, 68:5785-5793.

24. Starks AM, Bourdage KL, Thiaville PC, Gulig PA: Use of a marker plasmid to examine growth and death of Vibrio vulnificus in infected mice. $\mathrm{Mol}$ Microbiol 2006, 61:310-323.

25. DePaola A, Nordstrom JL, Dalsgaard A, Forslund A, Oliver JD, Bates T, Bourdage KL, Gulig PA: Analysis of Vibrio vulnificus from market oysters and septicemia cases for virulence markers. Appl Environ Microbiol 2003, 69:4006-4011.

26. Biosca EG, Llorens H, Garay E, Amaro C: Presence of a capsule in Vibrio vulnificus biotype 2 and its relationship to virulence for eels. Infect Immun 1993, 61:1611-1618. 
27. Li H, Ruan J, Durbin R: Mapping short DNA sequencing reads and calling variants using mapping quality scores. Genome Res 2008, 18:1851-1858.

28. Lee CT, Amaro C, Wu KM, Valiente E, Chang YF, Tsai SF, Chang CH, Hor LI: A common virulence plasmid in biotype 2 Vibrio vulnificus and its dissemination aided by a conjugal plasmid. J Bacteriol 2008, 190:1638-1648.

29. Davidson LS, Oliver JD: Plasmid carriage in Vibrio vulnificus and other lactose- fermenting marine vibrios. Appl Environ Microbiol 1986, 52:211-213.

30. Chen CY, Wu KM, Chang YC, Chang CH, Tsai HC, Liao TL, Liu YM, Chen HJ, Shen AB, Li JC, Su TL, Shao CP, Lee CT, Hor LI, Tsai SF: Comparative genome analysis of Vibrio vulnificus, a marine pathogen. Genome Res 2003, 13:2577-2587.

31. Labbate M, Case RJ, Stokes HW: The integron/gene cassette system: an active player in bacterial adaptation. Methods Mol Biol 2009, 532:103-125.

32. Mazel $D$, Dychinco B, Webb VA, Davies J: A distinctive class of integron in the Vibrio cholerae genome. Science 1998, 280:605-608.

33. Cotter PA, Stibitz S: c-di-GMP-mediated regulation of virulence and biofilm formation. Curr Opin Microbiol 2007, 10:17-23.

34. Kachlany SC, Planet PJ, DeSalle R, Fine DH, Figurski DH, Kaplan JB: flp-1, the first representative of a new pilin gene subfamily, is required for nonspecific adherence of Actinobacillus actinomycetemcomitans. Mol Microbiol 2001, 40:542-554.

35. Roberts DD, Ginsburg V: Sulfated glycolipids and cell adhesion. Arch Biochem Biophys 1988, 267:405-415.

36. Bhat S, Spitalnik SL, Gonzalez-Scarano F, Silberberg DH: Galactosyl ceramide or a derivative is an essential component of the neural receptor for human immunodeficiency virus type 1 envelope glycoprotein gp120. Proc Natl Acad Sci USA 1991, 88:7131-7134

37. Hannah JH, Menozzi FD, Renauld G, Locht C, Brennan MJ: Sulfated glycoconjugate receptors for the Bordetella pertussis adhesin filamentous hemagglutinin (FHA) and mapping of the heparin-binding domain on FHA. Infect Immun 1994, 62:5010-5019.

38. Kamisago S, Iwamori M, Tai T, Mitamura K, Yazaki Y, Sugano K: Role of sulfatides in adhesion of Helicobacter pylori to gastric cancer cells. Infect Immun 1996, 64:624-628.

39. Hoffman JA, Badger JL, Zhang Y, Huang SH, Kim KS: Escherichia coliK1 asIA contributes to invasion of brain microvascular endothelial cells in vitro and in vivo. Infect Immun 2000, 68:5062-5067.

40. Bryant $\mathrm{RG}$, Jarvis J, Janda JM: Use of sodium dodecyl sulfate-polymyxin Bsucrose medium for isolation of Vibrio vulnificus from shellfish. Appl Environ Microbiol 1987, 53:1556-1559.

41. Almagro-Moreno S, Boyd EF: Insights into the evolution of sialic acid catabolism among bacteria. BMC Evol Biol 2009, 9:118.

42. Jeong HG, Oh MH, Kim BS, Lee MY, Han HJ, Choi SH: The capability of catabolic utilization of $\mathrm{N}$-acetylneuraminic acid, a sialic acid, is essential for Vibrio vulnificus pathogenesis. Infect Immun 2009, 77:3209-3217.

43. Gu J, Neary J, Cai H, Moshfeghian A, Rodriguez SA, Lilburn TG, Wang Y: Genomic and systems evolution in Vibrionaceae species. BMC Genomics 2009, 10(Suppl 1):S11.

44. Fleischmann RD, Adams MD, White O, Clayton RA, Kirkness EF, Kerlavage AR, Bult CJ, Tomb JF, Dougherty BA, Merrick JM, McKenney K, Sutton G, Fitzhugh W, Fields C, Gocayne JD, Scott J, Shirley R, Liu LI, Glodek A, Kelley JM, Weidman JF, Phillips CA, Spriggs T, Hedblom E, Cotton MD, Utterback TR, Hanna MC, Nguyen DT, Saudek DM, Brandon RC, Fine LD, Fritchman JL, Fuhrmann JL, Geoghagen NSM, Gnehm CL, McDonald LA, Small KV, Fraser CM, Smith HO, Venter JC: Whole-genome random sequencing and assembly of Haemophilus-influenzae Rd. Science 1995, 269:496-512

45. Hall $\mathrm{N}$ : Advanced sequencing technologies and their wider impact in microbiology. J Exp Biol 2007, 210:1518-1525.

46. Sanger F, Nicklen $S$, Coulson AR: DNA sequencing with chain-terminating inhibitors. Proc Natl Acad Sci USA 1977, 74:5463-5467.

47. Hudson ME: Sequencing breakthroughs for genomic ecology and evolutionary biology. Mol Ecol Resour 2008, 8:3-17.

48. Mardis ER: The impact of next-generation sequencing technology on genetics. Trends Genet 2008, 24:133-141.

49. Morozova O, Marra MA: Applications of next-generation sequencing technologies in functional genomics. Genomics 2008, 92:255-264.
50. Pettersson E, Lundeberg J, Ahmadian A: Generations of sequencing technologies. Genomics 2009, 93:105-111.

51. Rothberg JM, Leamon JH: The development and impact of 454 sequencing. Nat Biotechnol 2008, 26:1117-1124.

52. Margulies M, Egholm M, Altman WE, Attiya S, Bader JS, Bemben LA, Berka J, Braverman MS, Chen YJ, Chen ZT, Dewell SB, Du L, Fierro JM, Gomes XV, Godwin BC, He W, Helgesen S, Ho CH, Irzyk GP, Jando SC, Alenquer MLI, Jarvie TP, Jirage KB, Kim JB, Knight JR, Lanza JR, Leamon JH, Lefkowitz SM, Lei M, Li J, Lohman KL, Lu H, Makhijani VB, McDade KE, McKenna MP, Myers EW, Nickerson E, Nobile JR, Plant R, Puc BP, Ronan MT, Roth GT, Sarkis GJ, Simons JF, Simpson JW, Srinivasan M, Tartaro KR, Tomasz A, Vogt KA, Volkmer GA, Wang SH, Wang Y, Weiner MP, Yu PG, Begley RF, Rothberg JM: Genome sequencing in microfabricated high-density picolitre reactors. Nature 2005, 437:376-380.

53. Hiller NL, Janto B, Hogg JS, Boissy R, Yu S, Powell E, Keefe R, Ehrlich NE, Shen K, Hayes J, Barbadora K, Klimke W, Dernovoy D, Tatusova T, Parkhill J, Bentley SD, Post JC, Ehrlich GD, Hu FZ: Comparative genomic analyses of seventeen Streptococcus pneumoniae strains: insights into the pneumococcal supragenome. J Bacteriol 2007, 189:8186-8195.

54. Adams MD, Goglin K, Molyneaux N, Hujer KM, Lavender H, Jamison Jj, MacDonald IJ, Martin KM, Russo T, Campagnari AA, Hujer AM, Bonomo RA, Gill SR: Comparative genome sequence analysis of multidrug-resistant Acinetobacter baumannii. J Bacteriol 2008, 190:8053-8064.

55. Snyder LAS, Loman N, Pallen MJ, Penn CW: Next-generation sequencingthe promise and perils of charting the great microbial unknown. Microbial Ecology 2009, 57:1-3.

56. Ley RE, Turnbaugh PJ, Klein S, Gordon Jl: Microbial ecology - Human gut microbes associated with obesity. Nature 2006, 444:1022-1023.

57. Turnbaugh PJ, Hamady M, Yatsunenko T, Cantarel BL, Duncan A, Ley RE, Sogin ML, Jones WJ, Roe BA, Affourtit JP, Egholm M, Henrissat B, Heath AC, Knight $\mathrm{R}$, Gordon Jl: A core gut microbiome in obese and lean twins. Nature 2009, 457:480-484.

58. Sogin ML, Morrison HG, Huber JA, Mark Welch D, Huse SM, Neal PR, Arrieta JM, Herndl GJ: Microbial diversity in the deep sea and the underexplored "rare biosphere". Proc Natl Acad Sci USA 2006, 103:12115-12120.

59. Cox-Foster DL, Conlan S, Holmes EC, Palacios G, Evans JD, Moran NA, Quan PL, Briese T, Hornig M, Geiser DM, Martinson V, vanEngelsdorp D, Kalkstein AL, Drysdale A, Hui J, Zhai JH, Cui LW, Hutchison SK, Simons JF, Egholm M, Pettis JS, Lipkin WI: A metagenomic survey of microbes in honey bee colony collapse disorder. Science 2007, 318:283-287.

60. Aury JM, Cruaud C, Barbe V, Rogier O, Mangenot S, Samson G, Poulain J, Anthouard V, Scarpelli C, Artiguenave F, Wincker P: High quality draft sequences for prokaryotic genomes using a mix of new sequencing technologies. Bmc Genomics 2008, 9:11.

61. Loman NJ, Pallen MJ: XDR-TB genome sequencing: a glimpse of the microbiology of the future. Future Microbiol 2008, 3:111-113.

62. Loman NJ, Snyder LAS, Linton JD, Langdon R, Lawson AJ, Weinstock GM, Wren BW, Pallen MJ: Genome sequence of the emerging pathogen Helicobacter canadensis. J Bacteriol 2009, 191:5566-5567.

63. Qi W, Kaser M, Roltgen K, Yeboah-Manu D, Pluschke G: Genomic diversity and evolution of Mycobacterium ulcerans revealed by next-generation sequencing. PLos Pathogens 2009, 5:e1000580.

64. Reinhardt JA, Baltrus DA, Nishimura MT, Jeck WR, Jones CD, Dangl JL: De novo assembly using low-coverage short read sequence data from the rice pathogen Pseudomonas syringae pv. oryzae. Genome Res 2009, 19:294-305.

65. Studholme DJ, Ibanez SG, MacLean D, Dangl JL, Chang JH, Rathjen JP: A draft genome sequence and functional screen reveals the repertoire of type III secreted proteins of Pseudomonas syringae pathovar tabaci 11528. Bmc Genomics 2009, 10:19.

66. Srivatsan A, Han Y, Peng JL, Tehranchi AK, Gibbs R, Wang JD, Chen R: Highprecision, whole-genome sequencing of laboratory strains facilitates genetic studies. PLOS Genet 2008, 4:14.

67. Holt KE, Parkhill J, Mazzoni CJ, Roumagnac P, Weill FX, Goodhead I, Rance R, Baker S, Maskell DJ, Wain J, Dolecek C, Achtman M, Dougan G: Highthroughput sequencing provides insights into genome variation and evolution in Salmonella Typhi. Nature Genet 2008, 40:987-993.

68. Hillier LW, Marth GT, Quinlan AR, Dooling D, Fewell G, Barnett D, Fox P, Glasscock Jl, Hickenbotham M, Huang WC, Magrini VJ, Richt RJ, Sander SN, 
Stewart DA, Stromberg M, Tsung EF, Wylie T, Schedl T, Wilson RK, Mardis ER: Whole-genome sequencing and variant discovery in $C$. elegans. Nat Methods 2008, 5:183-188.

69. Sarin S, Prabhu S, O'Meara MM, Pe'er I, Hobert O: Caenorhabditis elegans mutant allele identification by whole-genome sequencing. Nat Methods 2008, 5:865-867.

70. Shen Y, Sarin S, Liu Y, Hobert O, Pe'er I: Comparing platforms for $C$. elegans mutant identification using high-throughput whole-genome sequencing. Plos one 2008, 3:e4012.

71. Smith DR, Quinlan AR, Peckham HE, Makowsky K, Tao W, Woolf B, Shen L, Donahue WF, Tusneem N, Stromberg MP, Stewart DA, Zhang L, Ranade SS, Warner JB, Lee CC, Coleman BE, Zhang Z, McLaughlin SF, Malek JA, Sorenson JM, Blanchard AP, Chapman J, Hillman D, Chen F, Rokhsar DS, McKernan KJ, Jeffries TW, Marth GT, Richardson PM: Rapid whole-genome mutational profiling using next-generation sequencing technologies. Genome Res 2008, 18:1638-1642.

72. Antipova AA, Sokolsky TD, Clouser CR, Dimalanta ET, Hendrickson CL, Kosnopo C, Lee CC, Ranade SS, Zhang L, Blanchard AP, McKernan KJ: Polymorphism discovery in high-throughput resequenced microarrayenriched human genomic loci. Journal of Biomolecular Techniques 2009, 5:253-257

73. Chen W, Ullmann R, Langnick C, Menzel C, Wotschofsky Z, Hu H, Doring A, Hu Y, Kang H, Tzschach A, Hoeltzenbein M, Neitzel H, Markus S, Wiedersberg E, Kistner G, van Ravenswaaij-Arts CM, Kleefstra T, Kalscheuer VM, Ropers HH: Breakpoint analysis of balanced chromosome rearrangements by next-generation paired-end sequencing. European Journal of Human Genetics 2009, 18:539-543.

74. McKernan KJ, Peckham HE, Costa GL, McLaughlin SF, Fu YT, Tsung EF, Clouser CR, Duncan C, Ichikawa JK, Lee CC, Zhang Z, Ranade SS, Dimalanta ET, Hyland FC, Sokolsky TD, Zhang L, Sheridan A, Fu HN, Hendrickson CL, Li B, Kotler L, Stuart JR, Malek JA, Manning JM, Antipova AA, Perez DS, Moore MP, Hayashibara KC, Lyons MR, Beaudoin RE, Coleman BE, Laptewicz MW, Sannicandro AE, Rhodes MD, Gottimukkala RK, Yang S, Bafna V, Bashir A, MacBride A, Alkan C, Kidd JM, Eichler EE, Reese MG, De la Vega FM, Blanchard AP: Sequence and structural variation in a human genome uncovered by short-read, massively parallel ligation sequencing using two-base encoding. Genome Res 2009, 19:1527-1541.

75. Durfee T, Nelson R, Baldwin S, Plunkett G, Burland V, Mau B, Petrosino JF, Qin X, Muzny DM, Ayele M, Gibbs RA, Csorgo B, Posfai G, Weinstock GM, Blattner FR: The complete genome sequence of Escherichia coli DH10B: Insights into the biology of a laboratory workhorse. J Bacteriol 2008, 190:2597-2606.

76. Cummings CA, Bormann Chung CA, Fang R, Barker M, Brzoska PM, Williamson P, Beaudry JA, Matthews M, Schupp JM, Wagner DM, Furtado MR, Kiem P, Budowle B: Whole-genome typing of Bacillus anthracis isolates by next-generation sequencing accurately and rapidly identifies strain-specific diagnostic polymorphisms. Forensic Science International: Genetics Supplement Series 2009, 300-301.

77. Amaro C, Biosca EG, Fouz B, Toranzo AE, Garay E: Role of iron, capsule, and toxins in the pathogenicity of Vibrio vulnificus biotype 2 for mice. Infect Immun 1994, 62:759-763.

78. Amaro C, Biosca EG: Vibrio vulnificus biotype 2, pathogenic for eels, is also an opportunistic pathogen for humans. Appl Environ Microbiol 1996, 62:1454-1457.

79. Heidelberg JF, Eisen JA, Nelson WC, Clayton RA, Gwinn ML, Dodson RJ, Haft DH, Hickey EK, Peterson JD, Umayam L, Gill SR, Nelson KE, Read TD, Tettelin H, Richardson D, Ermolaeva MD, Vamathevan J, Bass S, Qin H, Dragoi I, Sellers P, McDonald L, Utterback T, Fleishmann RD, Nierman WC, White O: DNA sequence of both chromosomes of the cholera pathogen Vibrio cholerae. Nature 2000, 406:477-483.

80. Chun J, Grim CJ, Hasan NA, Lee JH, Choi SY, Haley BJ, Taviani E, Jeon YS, Kim DW, Lee JH, Brettin TS, Bruce DC, Challacombe JF, Detter JC, Han CS, Munk AC, Chertkov O, Meincke L, Saunders E, Walters RA, Huq A, Nair GB, Colwell RR: Comparative genomics reveals mechanism for short-term and long-term clonal transitions in pandemic Vibrio cholerae. Proc Natl Acad Sci USA 2009, 106:15442-15447.

81. Paley SM, Karp PD: The Pathway Tools cellular overview diagram and Omics Viewer. Nucleic Acids Res 2006, 34:3771-3778.

82. Overbeek R, Begley T, Butler RM, Choudhuri JV, Chuang HY, Cohoon M, Crecy-Lagard V, Diaz N, Disz T, Edwards R, Fonstein M, Frank ED, Gerdes S,
Glass EM, Goesmann A, Hanson A, Iwata-Reuyl D, Jensen R, Jamshidi N, Krause L, Kubal M, Larsen N, Linke B, McHardy AC, Meyer F, Neuweger $H$, Olsen G, Olson R, Osterman A, Portnoy V, Pusch GD, Rodionov DA, Ruckert C, Steiner J, Stevens R, Thiele I, Vassieva O, Ye Y, Zagnitko O, Vonstein $\mathrm{V}$ : The subsystems approach to genome annotation and its use in the project to annotate 1000 genomes. Nucleic Acids Res 2005, 33:5691-5702.

83. Mahmud ZH, Wright AC, Mandal SC, Dai J, Jones MK, Hasan M, Rashid MH, Islam MS, Johnson JA, Gulig PA, Morris JG Jr, Ali A: Genetic characterization of Vibrio vulnificus strains from tilapia aquaculture in Bangladesh. Appl Environ Microbiol 2010, 76:4890-4895.

84. Vickery MC, Nilsson WB, Strom MS, Nordstrom JL, DePaola A: A real-time PCR assay for the rapid determination of 16 S rRNA genotype in Vibrio vulnificus. J Microbiol Methods 2007, 68:376-384.

\section{doi:10.1186/1471-2164-11-512}

Cite this article as: Gulig et al:: SOLiD sequencing of four Vibrio vulnificus genomes enables comparative genomic analysis and identification of candidate clade-specific virulence genes. BMC Genomics 2010 11:512.

\section{Submit your next manuscript to BioMed Central and take full advantage of:}

- Convenient online submission

- Thorough peer review

- No space constraints or color figure charges

- Immediate publication on acceptance

- Inclusion in PubMed, CAS, Scopus and Google Scholar

- Research which is freely available for redistribution

Submit your manuscript at www.biomedcentral.com/submit
Biomed Central 